\title{
Generational Differences in Complementary and Alternative Medicine (CAM) Use in the Context of Chronic Diseases and Pain: Baby Boomers versus the Silent Generation
}

\author{
Tiffany F. Ho, BS, Anastasia Rowland-Seymour, MD, Eitan S. Frankel, BS, \\ Susan Q. Li, MS, and Jun J. Mao, MD, MSCE
}

Background: More people are supplementing conventional medicine with complementary and alternative medicine (CAM), but studies have not compared CAM use between baby boomers (adults born from 1946 to 1964) and the so-called silent generation (born from 1925 to 1945).

Methods: This study compares CAM usage between baby boomers $(n=7734)$ and the silent generation $(n=4682)$ through secondary analyses of the 2007 National Health Interview Survey data. The analysis also compares chronic disease and pain status. Multivariate logistic regression models were developed to identify generational differences.

Results: Although the silent generation reported twice as many chronic disease $(51.3 \% \mathrm{vs} 26.1 \%$; $P<.001)$ and more painful conditions $(56.1 \%$ vs $52.2 \% ; P<.001)$, baby boomers were more likely to use CAM within the past year $(43.1 \%$ vs $35.4 \% ; P<.001)$. Adjusting for covariates, baby boomers with heart disease, cancer, and diabetes were more likely to use CAM than adults from the silent generation. Chronic pain status was independently associated with greater CAM use (adjusted odds ratio, 2.26; 95\% confidence interval, 2.03-2.52).

Conclusions: Baby boomers reported significantly higher rates of CAM use than the silent generation for both chronic diseases and painful conditions. Family physicians caring for the aging population must use patient-centered communication about the risks/benefits of CAM, which is necessary to promote effective coping with chronic illnesses and pain. (J Am Board Fam Med 2014;27:465-473.)

Keywords: Aging, Alternative Medicine, Chronic Disease, Epidemiology, Pain

With dramatic improvements in public health, clinical care, and health technology, the average human lifespan in the United States has increased.

This article was externally peer reviewed.

Submitted 17 August 2013; revised 23 April 2014; accepted 30 April 2014.

From the Johns Hopkins University School of Medicine, Baltimore (TFH); Division of Internal Medicine (ARS), Johns Hopkins Hospital, Baltimore; and Department of Family Medicine and Community Health (ESF, SQL, JJM), Perelman School of Medicine at University of Pennsylvania, Philadelphia.

Funding: This study was conducted with the financial support of the Johns Hopkins University Dean's Research Funds and support from the National Institute of Health and National Center for Complementary and Alternative Medicine (5K23 AT004112-5)

Conflict of interest: none declared.

Corresponding author: Jun J. Mao, Department of Family Medicine and Community Health, University of Pennsylvania Health System, 2 Gates Bldg, 3400 Spruce St, Philadelphia, PA 19104-4283 (E-mail: jun.mao@uphs.upenn.edu).
When the last of the baby boomer generation, individuals born between 1946 to 1964, reaches the age of 65 in 2030, the population of older adults will double to 71 million, constituting $20 \%$ of the US population. ${ }^{1,2}$ Although the baby boomers have a longer life expectancy than the previous cohort, the silent generation (born 1925 to 1945), baby boomers will have higher rates of chronic conditions such as diabetes, hypertension, and cancer than their predecessors. ${ }^{3-7}$ The increasing proportion of older adults with comorbidities requires innovative strategies to help individuals cope with and prevent aging-related functional decline.

One area of health care that more people are turning to is complementary and alternative medicine (CAM), a group of modalities, practices, and products that either supplement or substitute con- 
ventional medicine. ${ }^{8}$ In 2007, almost 4 of 10 adults reported using CAM within the past 12 months. Data indicate that middle-aged and older adults seek CAM to manage their chronic illnesses and improve quality of life. ${ }^{9-11}$ In particular, adults with chronic conditions such as arthritis, hypertension, chronic pain, or cancer use CAM significantly more than adults without such diseases. ${ }^{12-18}$

Despite these emerging data demonstrating the effectiveness of CAM, little is known about generational differences of CAM use, especially in the context of chronic diseases and chronic pain. ${ }^{19}$ Previous studies examined CAM use in older adults age $\geq 65$ years, but baby boomers have not been included. ${ }^{11,13,20}$ In addition, studies focused on CAM use among patients with one specific chronic disease but lacked a comprehensive examination of CAM use across multiple chronic diseases in older adults. ${ }^{18}$ Because family physicians play a major role in caring of the aging populations with chronic illnesses, this knowledge is especially important to guide appropriate patient-centered care. In this article we analyze a nationally representative sample to evaluate CAM use of the baby boomers compared with the silent generation, focusing on chronic disease and pain. Understanding the differences in CAM usage between generations helps inform research and health policy to better meet the needs of aging baby boomers.

\section{Methods}

The National Health Interview Survey (NHIS) is an annual population-based, cross-sectional survey conducted by the Centers for Disease Control and Prevention's National Center for Health Statistics. ${ }^{21}$ Our study combined data collected from the 2007 sample adult core and the CAM file. Details on the survey design and content can be found online (http://www.cdc.gov/nchs/nhis.htm; last accessed July 20, 2012). This study was approved by the institutional review board at Johns Hopkins University.

\section{Baby Boomers and the Silent Generation}

Self-reported age was used to define each generation. Baby boomers include adults born between 1946 to 1964 and who in 2007 were between the ages of 43 and $61 .^{2}$ The silent generation includes adults born between 1925 to 1945 and who in 2007 were between the ages of 62 and 82 .

\section{CAM Use}

The National Center for Complementary and Alternative Medicine defines CAM as a group of diverse systems, practices, and products used in the health care field that are not considered part of conventional medicine. ${ }^{8}$ CAM therapies are grouped into 5 broad categories: alternative medical system, biologically based, manipulative and body based, mind-body based, and energy medicine. ${ }^{8,22}$ In the 2007 NHIS, adults were asked about their use of 38 CAM therapies in the past 12 months. CAM use was defined as a response of "yes" to any of the specific therapies.

\section{Chronic Diseases}

We defined chronic diseases according to a Centers for Disease Control and Prevention report that identified heart disease, cancer, stroke, lung disease, and diabetes as the leading causes of death in the United States. ${ }^{4}$ Heart disease status was determined by people who responded "yes" to any of the following questions: "Have you EVER been told by a doctor or health professional that you had coronary heart disease?" "Have you EVER been told by a doctor or health professional that you had angina pectoris?" or "Have you EVER been told by a doctor or health professional that you had a heart attack?" Cancer status was based on the question, "Have you EVER been told by a doctor or health professional that you had cancer or a malignancy of any kind?" We included every type except nonmelanoma skin cancer. Stroke status was determined by people who responded "yes" to "Have you EVER been told by a doctor or health professional that you had a stroke?" Lung disease was assessed by an affirmative response to any of the following questions: "During the past 12 months have you had emphysema?" "Do you still have asthma?" or "Have you been told by a doctor or health professional that you have chronic bronchitis?" Diabetes status was determined by people who responded "yes" to the question, "Have you EVER been told by a doctor or health professional that you have diabetes or sugar diabetes?"

\section{Painful Conditions}

Pain status was determined by people who responded "yes" to any of the following questions: "During the past 30 days, have you had any symptoms of pain, aching, or stiffness in or around a joint?" or "Please refer to pain that lasted a whole 
day or more. During the past 3 months, did you have: neck pain, lower back pain, facial ache or pain in the jaw muscles or the joint in front of the ear (facial pain), severe headache or migraine (head pain)?”

\section{Covariates}

Self-reported demographic variables included sex, education, race/ethnicity, census region, and body mass index. Education was classified as high school graduate or less, some college or technical school, and college or a more advanced degree. Geographic locations were based on US census regions: Northeast, Midwest, South, and West. We defined race/ethnic group as non-Hispanic white, non-Hispanic black, Hispanic, and Asian. For analysis purposes, we created 3 body mass index categories: normal $\left(<25 \mathrm{~kg} / \mathrm{m}^{2}\right)$, overweight $\left(25-29 \mathrm{~kg} / \mathrm{m}^{2}\right)$, and obese $\left(\geq 30 \mathrm{~kg} / \mathrm{m}^{2}\right)$.

\section{Statistical Analysis}

All statistical analyses were performed using STATA version 12 (StataCorp, College Station, TX). We accounted for the complex survey design used to collect NHIS data by using survey-specific commands. ${ }^{23}$ We first compared demographic and health characteristics between the 2 generations and then tested the generational differences in CAM use with univariate logistic regression. We then evaluated the proportion of CAM use among a subpopulation of people with and without a particular health condition in each cohort and compared it with the other age group.

To identify factors that were associated with CAM use in each generation, we developed multivariate logistic regression models. One model identified independent predictors for CAM use while adjusting for sex, race/ethnicity, education, census region, chronic disease, and painful condition. Another model identified chronic diseases or painful conditions as predictors of CAM use while adjusting for sociodemographics. Statistical tests were 2 -sided; $P<.05$ indicated significance.

\section{Results}

The 2007 NHIS sampled 23,393 adults $\geq 18$ years old, with a response rate of $67.8 \% .{ }^{24}$ Among these, $12,416(53.1 \%)$ were categorized as either the silent generation or baby boomer generation. A total of $7734(33.1 \%)$ respondents were baby boomers, representing 76 million Americans, and 4682 $(20.0 \%)$ were of the silent generation, representing 36 million Americans.

\section{Characteristics of Baby Boomers and the Silent Generation}

The baby boomer cohort was significantly more educated, racially/ethnically diverse, and obese than the silent generation (Table 1). Of the silent generation, $51 \%$ reported having a chronic disease compared with $26.1 \%$ of the baby boomers; the older cohort had a substantially higher prevalence of every chronic disease category $(P<.001$ for all categories). For example, the silent generation was 3 times more likely to have heart disease $(18.5 \%$ vs $5.4 \%)$ and cancer $(16.0 \%$ vs $5.5 \%)$ than baby boomers.

Overall the silent generation reported a slightly higher prevalence of painful conditions than baby boomers $(56.1 \%$ vs $52.2 \% ; P<.001)$. Although baby boomers were less likely to have specific joint pain $(34.7 \%$ vs $43.1 \%$; $P<.001)$, the younger cohort reported more facial pain $(4.9 \%$ vs $2.8 \%$; $P<.001)$ and head pain $(13.2 \%$ vs $5.7 \% ; P<.001)$ than the silent generation.

\section{CAM Use Among Baby Boomers versus the Silent Generation}

Baby boomers reported higher rates of CAM use within the past 12 months than the silent generation $(43.1 \%$ vs $36.4 \% ; P<.001$ ) (Table 2 ). Baby boomers were more likely to use a modality in each of the major CAM categories $(23.3 \%$ vs $22.4 \%$; $P=.32$ ), except for biologically based CAM. The younger generation was twice as likely to report accessing alternative medical systems $(4.5 \%$ vs $2.2 \% ; P<.001)$. For manipulative and body-based therapies, twice as many baby boomers reported using massage $(9.6 \%$ vs $4.8 \% ; P<.001)$. Of baby boomers, $21 \%$ reported using mind-body medicine compared with $13.7 \%$ of the silent generation. Within the mind-body category, baby boomers were almost twice as likely to pursue meditation $(11.5 \%$ vs $6.7 \% ; P<.001)$ and yoga $(5.9 \%$ vs $2.2 \%$; $P<.001)$.

Multivariate analysis revealed baby boomers had significantly greater odds of CAM use within the past year (adjusted odds ratio [AOR], 1.30; 95\% confidence interval [CI], 1.17-1.44) (Table 3). Similarly, compared with the silent generation, baby boomers were significantly more likely to use alter- 
Table 1. Characteristics of Participants: Baby Boomers versus the Silent Generation

\begin{tabular}{|c|c|c|c|c|c|}
\hline \multirow[b]{2}{*}{ Characteristics } & \multicolumn{2}{|c|}{$\begin{array}{l}\text { Baby Boomers } \\
(\mathrm{n}=7734)\end{array}$} & \multicolumn{2}{|c|}{$\begin{array}{l}\text { Silent Generation } \\
\qquad(\mathrm{n}=4682)\end{array}$} & \multirow[b]{2}{*}{$P$ Value } \\
\hline & $\%$ & SE & $\%$ & SE & \\
\hline \multicolumn{6}{|l|}{ Demographics } \\
\hline Sex & & & & & .003 \\
\hline Male & 48.27 & 0.64 & 44.84 & 0.91 & \\
\hline Female & 51.73 & 0.64 & 55.16 & 0.91 & \\
\hline Educational attainment & & & & & $<.001$ \\
\hline High school or less & 41.24 & 0.72 & 56.63 & 1.01 & \\
\hline Some college or technical school & 27.53 & 0.63 & 21.09 & 0.74 & \\
\hline College or more advanced & 31.23 & 0.77 & 22.28 & 0.82 & \\
\hline Race/ethnicity & & & & & $<.001$ \\
\hline Non-Hispanic white & 73.85 & 0.71 & 80.35 & 0.69 & \\
\hline Non-Hispanic black & 11.40 & 0.48 & 8.94 & 0.44 & \\
\hline Hispanic & 10.55 & 0.48 & 7.23 & 0.48 & \\
\hline Asian & 4.20 & 0.28 & 3.48 & 0.28 & \\
\hline Census region & & & & & .44 \\
\hline Northeast & 17.45 & 0.65 & 18.50 & 0.85 & \\
\hline Midwest & 24.13 & 1.00 & 24.47 & 0.98 & \\
\hline South & 36.52 & 0.98 & 36.54 & 1.15 & \\
\hline West & 21.90 & 0.76 & 20.48 & 0.89 & \\
\hline \multicolumn{6}{|l|}{ Clinical Factors } \\
\hline Body mass index & & & & & $<.001$ \\
\hline Normal $\left(<25 \mathrm{~kg} / \mathrm{m}^{2}\right)$ & 32.00 & 0.62 & 34.51 & 0.76 & \\
\hline Overweight $\left(25-29.99 \mathrm{~kg} / \mathrm{m}^{2}\right)$ & 37.39 & 0.69 & 40.00 & 0.77 & \\
\hline Obese $\left(\geq 30 \mathrm{~kg} / \mathrm{m}^{2}\right)$ & 30.62 & 0.68 & 25.48 & 0.72 & \\
\hline Chronic disease & 26.07 & 0.62 & 51.30 & 0.86 & $<.001$ \\
\hline Heart disease* & 5.42 & 0.33 & 18.52 & 0.74 & $<.001$ \\
\hline Diabetes & 9.53 & 0.39 & 19.05 & 0.69 & $<.001$ \\
\hline Cancer $^{\dagger}$ & 5.54 & 0.31 & 16.01 & 0.65 & $<.001$ \\
\hline Lung disease $\mathrm{e}^{\ddagger}$ & 10.05 & 0.39 & 13.21 & 0.61 & $<.001$ \\
\hline Stroke & 2.46 & 0.23 & 6.79 & 0.43 & $<.001$ \\
\hline Painful condition & 52.20 & 0.69 & 56.07 & 0.93 & $<.001$ \\
\hline Neck pain & 15.96 & 0.50 & 14.70 & 0.59 & .10 \\
\hline Lower-back pain & 28.26 & 0.60 & 29.28 & 0.76 & .28 \\
\hline Facial pain & 4.86 & 0.29 & 2.76 & 0.27 & $<.001$ \\
\hline Head pain & 13.16 & 0.48 & 5.70 & 0.39 & $<.001$ \\
\hline Joint pain & 34.72 & 0.68 & 43.14 & 0.90 & $<.001$ \\
\hline
\end{tabular}

${ }^{*}$ Heart disease includes coronary heart disease, heart attack, other heart condition.

${ }^{\dagger}$ Cancer includes any cancer except nonmelanoma cancer.

${ }^{\ddagger}$ Lung disease includes asthma, emphysema, or chronic bronchitis in the past 12 months.

SE, standard error.

native medical system, manipulative-based, mindbody, and energy therapies (Table 2).

\section{CAM Use Among Baby Boomers and the Silent Generation With Chronic Diseases}

Among the subset of individuals with chronic diseases, CAM use was consistently higher among baby boomers compared with the silent generation (44.8\% vs $36.7 \% ; P<.001$ ) (Figure 1). The younger generation with heart disease, diabetes, or cancer was significantly more likely to report using CAM. For example, within the past year, $40.5 \%$ of the silent generation with cancer reported using CAM, and more than half (52.1\%) of the baby boomers with cancer reported using CAM. 
Table 2. Use of Complementary and Alternative Medicine (CAM) in the Past 12 Months: Baby Boomers versus the Silent Generation

\begin{tabular}{|c|c|c|c|c|c|}
\hline \multirow[b]{2}{*}{ CAM Use } & \multicolumn{2}{|c|}{$\begin{array}{l}\text { Baby } \\
\text { Boomers }\end{array}$} & \multicolumn{2}{|c|}{$\begin{array}{c}\text { Silent } \\
\text { Generation }\end{array}$} & \multirow[b]{2}{*}{$P$ Value } \\
\hline & $\%$ & SE & $\%$ & SE & \\
\hline Any CAM therapy & 43.05 & 0.81 & 36.41 & 0.91 & $<.001$ \\
\hline $\begin{array}{l}\text { Alternative medical } \\
\text { systems }\end{array}$ & 4.54 & 0.28 & 2.16 & 0.23 & $<.0001$ \\
\hline Acupuncture & 2.09 & 0.18 & 1.17 & 0.18 & .001 \\
\hline Ayurveda & 0.07 & - & 0.05 & - & .68 \\
\hline Homeopathy & 2.28 & 0.18 & 0.82 & 0.14 & $<.001$ \\
\hline Naturopathy & 0.51 & 0.10 & 0.31 & 0.10 & .12 \\
\hline Traditional healers* & 0.34 & 0.11 & 0.13 & - & .02 \\
\hline Biologically based & 23.30 & 0.68 & 22.39 & 0.76 & .32 \\
\hline Chelation therapy & 0.09 & - & 0.09 & - & .91 \\
\hline Herbs & 20.67 & 0.63 & 20.89 & 0.72 & .80 \\
\hline Special diets ${ }^{\dagger}$ & 4.38 & 0.29 & 2.72 & 0.29 & $<.001$ \\
\hline $\begin{array}{c}\text { Manipulative and } \\
\text { body based }\end{array}$ & 17.40 & 0.6 & 11.64 & 0.60 & $<.001$ \\
\hline $\begin{array}{l}\text { Chiropractic/ } \\
\text { osteopathic }\end{array}$ & 10.16 & 0.44 & 8.09 & 0.51 & .002 \\
\hline Massage & 9.57 & 0.43 & 4.81 & 0.39 & $<.001$ \\
\hline Movement based ${ }^{\ddagger}$ & 1.51 & 0.16 & 0.35 & 0.11 & $<.001$ \\
\hline Mind-body & 21.06 & 0.69 & 13.73 & 0.58 & $<.001$ \\
\hline Biofeedback & 0.23 & 0.07 & 0.08 & 一 & .10 \\
\hline Meditation & 11.45 & 0.54 & 6.72 & 0.42 & $<.001$ \\
\hline Guided imagery & 3.23 & 0.35 & 1.13 & 0.18 & $<.001$ \\
\hline $\begin{array}{l}\text { Progressive } \\
\text { relaxation }\end{array}$ & 4.32 & 0.31 & 1.69 & 0.22 & $<.001$ \\
\hline Deep breathing & 15.08 & 0.61 & 9.53 & 0.48 & $<.001$ \\
\hline Hypnosis & 0.45 & 0.09 & 0.15 & - & .02 \\
\hline Stress management & 1.17 & 0.15 & 0.31 & 0.07 & $<.001$ \\
\hline Support groups & 2.37 & 0.21 & 1.09 & 0.17 & $<.001$ \\
\hline Yoga & 5.90 & 0.33 & 2.20 & 0.28 & $<.001$ \\
\hline Tai chi & 1.06 & 0.12 & 1.05 & 0.17 & .94 \\
\hline Qi gong & 0.41 & 0.08 & 0.22 & 0.07 & .10 \\
\hline Energy healing/Reiki & 0.87 & 0.12 & 0.32 & 0.09 & .001 \\
\hline
\end{tabular}

*Traditional healers include curandero, espiritista, hierbero, shaman, botanica, Native American healer, and sobador.

${ }^{\dagger}$ Special diets include vegetarian, macrobiotic, Atkins, Pritikin, Ornish, The Zone, and South Beach.

* Movement-based therapies include Feldenkreis, Alexander technique, Pilates, and Trager.

SE, standard error.

After adjusting for demographic factors (Table 4), baby boomers with chronic diseases were significantly more likely to use CAM than their predecessors (AOR, 1.38; 95\% CI, 1.17-1.63). The largest generational gaps between baby boomers and the silent generation are related to diabetes (AOR, 1.64; 95\% CI, 1.25-2.15), cancer (AOR, 1.60; 95\%
CI, 1.22-2.10), and heart disease (AOR, 1.55; 95\% CI, 1.15-2.10).

\section{CAM Use Among Baby Boomers and the Silent Generation With Painful Conditions}

Among adults who experienced pain, baby boomers were more likely to report using CAM compared with the silent generation $(52.9 \%$ vs $43.1 \% ; P<$ .001 ), as illustrated in Figure 2. Baby boomers with facial pain had dramatically higher rates of CAM use compared with the older cohort $(70.2 \%$ vs $47.7 \% ; P<.001)$, followed by baby boomers with neck pain $(61.5 \%$ vs $51.3 \% ; P<.001)$. After adjusting for demographic variables (Table 4), the younger cohort was $38 \%$ more likely to use CAM (AOR, 1.38; 95\% CI, 1.21-1.57).

Within each generation, adults with a painful condition were substantially more likely to pursue CAM than adults without pain (Figure 2). For baby boomers, CAM use within the past 12 months increased from $32.3 \%$ to $52.9 \%$ if the adult reported having a painful condition. CAM use also increased in the silent generation, from $28.0 \%$ to $43.1 \%$, among adults with a painful condition. Multivariate analysis revealed adults with a painful condition were twice as likely to use CAM than adults without pain (AOR, 2.26; 95\% CI, 2.032.52) (Table 3).

\section{Discussion}

In this study we analyzed generational differences of CAM use between the baby boomers and the silent generation in the context of chronic diseases and painful conditions. While the silent generation reported a substantially higher prevalence of chronic diseases, interestingly, the baby boomers reported higher CAM use regardless of health status. The generational differences of CAM use were greatest in those with diabetes, cancer, and heart disease. Furthermore, individuals with chronic pain were significantly more likely to use CAM than those without pain. Taken together, these data suggest that baby boomers are already using CAM significantly more, and this usage may continue to rise as chronic diseases and painful conditions increase.

Although baby boomers currently report fewer chronic diseases, rates are expected to increase exponentially. By 2030, more than 6 in 10 baby boomers will be managing at least 1 chronic dis- 
Table 3. Independent Predictors of Complementary and Alternative Medicine (CAM) Use Among Baby Boomers and the Silent Generation

\begin{tabular}{|c|c|c|c|c|}
\hline \multirow[b]{2}{*}{ Predictors of CAM Use } & \multicolumn{2}{|c|}{ Univariate Analyses } & \multicolumn{2}{|c|}{ Multivariate Model $^{*}$} \\
\hline & OR & $95 \% \mathrm{CI}$ & AOR & $95 \% \mathrm{CI}$ \\
\hline \multicolumn{5}{|l|}{ Generation } \\
\hline Silent generation & \multicolumn{2}{|c|}{ Reference } & \multicolumn{2}{|c|}{ Reference } \\
\hline Baby Boomer & 1.32 & $1.20-1.45$ & 1.30 & $1.17-1.44$ \\
\hline \multicolumn{5}{|l|}{ Sex } \\
\hline Male & \multicolumn{2}{|c|}{ Reference } & \multicolumn{2}{|c|}{ Reference } \\
\hline Female & 1.46 & $1.35-1.58$ & 1.52 & $1.40-1.65$ \\
\hline \multicolumn{5}{|l|}{ Education attainment } \\
\hline High school or less & \multicolumn{2}{|c|}{ Reference } & \multicolumn{2}{|c|}{ Reference } \\
\hline Some college or technical school & 2.16 & $1.95-2.40$ & 2.01 & $1.79-2.25$ \\
\hline College or more advanced & 2.59 & $2.33-2.88$ & 2.69 & $2.40-3.02$ \\
\hline \multicolumn{5}{|l|}{ Race/ethnicity } \\
\hline Non-Hispanic white & \multicolumn{2}{|c|}{ Reference } & \multicolumn{2}{|c|}{ Reference } \\
\hline Hispanic & 0.45 & $0.39-0.52$ & 0.52 & $0.44-0.60$ \\
\hline Non-Hispanic black & 0.45 & $0.39-0.52$ & 0.51 & $0.44-0.60$ \\
\hline Asian & 0.75 & $0.56-1.01$ & 0.68 & $0.49-0.93$ \\
\hline \multicolumn{5}{|l|}{ Census region } \\
\hline Northeast & \multicolumn{2}{|c|}{ Reference } & \multicolumn{2}{|c|}{ Reference } \\
\hline Midwest & 1.21 & $1.05-1.39$ & 1.16 & $1.01-1.34$ \\
\hline South & 0.85 & $0.74-0.98$ & 0.89 & $0.78-1.02$ \\
\hline West & 1.51 & $1.32-1.72$ & 1.48 & $1.28-1.70$ \\
\hline \multicolumn{5}{|l|}{ Chronic disease } \\
\hline No chronic disease & \multicolumn{2}{|c|}{ Reference } & \multicolumn{2}{|c|}{ Reference } \\
\hline Have chronic diseases & 0.99 & $0.91-1.09$ & 1.04 & $0.94-1.15$ \\
\hline \multicolumn{5}{|l|}{ Painful condition } \\
\hline No painful condition & \multicolumn{2}{|c|}{ Reference } & \multicolumn{2}{|c|}{ Reference } \\
\hline Have painful conditions & 2.19 & $1.97-2.43$ & 2.26 & $2.03-2.52$ \\
\hline
\end{tabular}

${ }^{*}$ Model adjusted for demographics, chronic diseases, and painful conditions.

AOR, adjusted odds ratio; CI, confidence interval; OR, odds ratio.

ease. Obesity is a major risk factor for both chronic diseases and painful conditions, and our study showed that baby boomers were significantly more obese than their predecessors. ${ }^{4,25}$ Baby boomers also were more educated and diverse than the silent generation. As demands for health services increase, baby boomers will seek new approaches to health care to address their unique needs and expectations.

Even after adjusting for demographic variables and health status, baby boomers are $30 \%$ more likely to use CAM than the silent generation. This higher CAM use is possibly attributed to the resurgence of the holistic health movement in the 1970s, when baby boomers were young adults. ${ }^{26-28}$ Early exposure to massage, relaxation techniques, yoga, and other alternative practices could have influenced their later use of CAM. Furthermore, the movement for self-care occurred shortly after, and CAM may provide people with a better sense of control and responsibility over the management of their disease. ${ }^{28,29}$

We hypothesize that more baby boomers will turn to CAM because of a growing interest in self-management programs that emphasize the patient's role in managing chronic diseases. Previous studies reported older adults integrating CAM with conventional practices to treat daily symptoms related to their chronic disease. ${ }^{29}$ Herbs, dietary supplements, and mind-body medicine are commonly reported modalities for self-management. ${ }^{18}$ Current clinical trials for mind-body approaches such tai chi and yoga show emerging evidence demonstrating an improvement in quality of life for those with chronic diseases. ${ }^{30}$ More research is needed to evaluate the effectiveness and optimal integration 
Figure 1. Use of complementary and alternative medicine in the past year by adults with chronic diseases: baby boomers versus the silent generation.

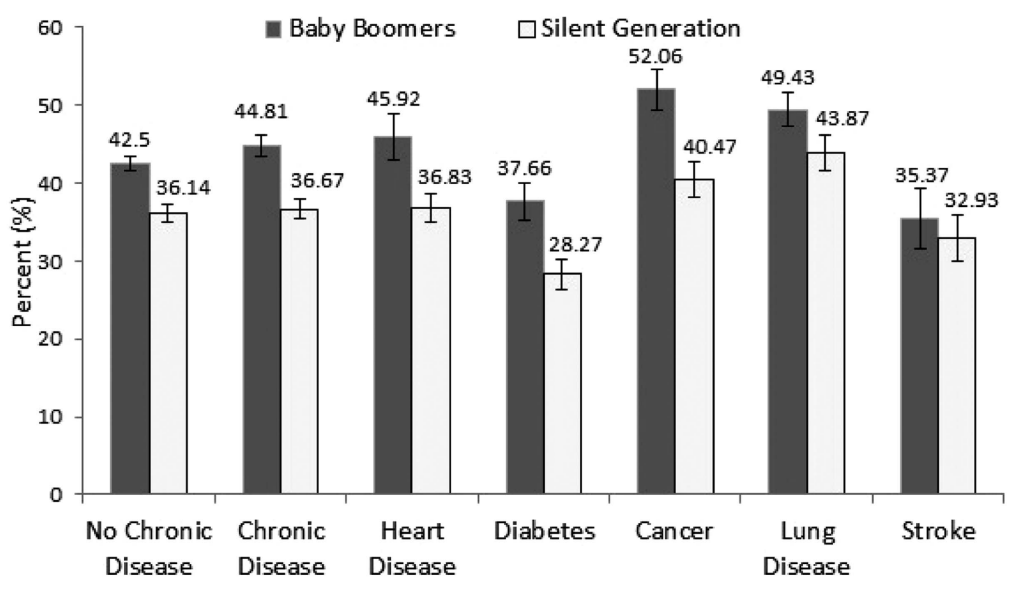

of CAM into the conventional health system and to improve chronic disease management.

Pain is one of the most cited reasons for CAM use, often because conventional treatments are not completely effective or medications have undesired side effects. ${ }^{31,32}$ One in 2 adults in our study reported having a pain condition. While the prevalence of neck and low-back pain were comparable between the 2 generations, the baby boomers were more likely to report head and facial pain. Several nonpharmacological interventions, such as acupuncture, ${ }^{33}$ tai chi, ${ }^{34}$ yoga,${ }^{35}$ and massage, ${ }^{36}$ have shown evidence in managing chronic pain.

Table 4. Complementary and Alternative Medicine (CAM) Use for Specific Conditions Among Baby Boomer and the Silent Generation

\begin{tabular}{|c|c|c|c|c|}
\hline \multirow[b]{2}{*}{ Conditions } & \multicolumn{2}{|c|}{ Univariate } & \multicolumn{2}{|c|}{ Multivariate* } \\
\hline & OR & $95 \% \mathrm{CI}$ & OR & $95 \% \mathrm{CI}$ \\
\hline Chronic disease & 1.40 & $1.20-1.63$ & 1.38 & $1.17-1.63$ \\
\hline Heart disease & 1.46 & $1.09-1.96$ & 1.55 & $1.15-2.10$ \\
\hline Diabetes & 1.53 & $1.17-2.00$ & 1.64 & $1.25-2.15$ \\
\hline Cancer & 1.60 & $1.23-2.07$ & 1.60 & $1.22-2.10$ \\
\hline Lung disease & 1.25 & $0.97-1.61$ & 1.22 & $0.93-1.60$ \\
\hline Stroke & 1.11 & $0.72-1.72$ & 1.08 & $0.68-1.72$ \\
\hline Painful condition & 1.48 & $1.31-1.67$ & 1.38 & $1.21-1.57$ \\
\hline Neck pain & 1.51 & $1.21-1.90$ & 1.50 & $1.18-1.90$ \\
\hline Lower-back pain & 1.21 & $1.02-1.44$ & 1.16 & $0.97-1.39$ \\
\hline Facial pain & 2.58 & $1.56-4.25$ & 2.07 & $1.18-3.64$ \\
\hline Head pain & 1.60 & $1.12-2.28$ & 1.59 & $1.11-2.28$ \\
\hline Joint pain & 1.56 & $1.36-1.78$ & 1.43 & $1.23-1.65$ \\
\hline
\end{tabular}

*Multivariate analyses adjusted for demographic factors.

CI, confidence interval; OR, odds ratio.
Thoughtful research and incorporation of these strategies in the existing health care system may help the aging population to deal with chronic pain and avoid the potential for unnecessary poly-pharmacy and its unintended health consequences.

This study had several limitations. First, the NHIS data are based on self-reported health status and CAM use, which is inherently subject to recall bias, varied interpretation, and measurement errors. Second, the NHIS does not include military personnel, institutionalized individuals, or terminally ill patients who may have different patterns of CAM use. The third major limitation is that we could not evaluate the causal relationship between aging, chronic diseases, painful conditions, and CAM use given the cross-sectional design of the NHIS. Our analyses are meant to be descriptive and inform the understanding of differences in CAM use between baby boomers and the silent generation with respect to chronic diseases and pain.

Despite these limitations, our study is the first to provide a detailed population-based comparison of the health status of and CAM usage among 2 aging generations, with a special focus on chronic diseases and painful conditions. Baby boomers were more likely to use CAM than the silent generation across multiple chronic diseases and pain conditions. The prevalence of chronic diseases and painful conditions will continue to rise as baby boomers age, challenging our health care system. Our findings suggest future research should test the safety, effectiveness, and optimal integration of CAM for aging-related health issues. Because of the substan- 
Figure 2. Use of complementary and alternative medicine in the past year by adults with painful conditions: baby boomers versus the silent generation.

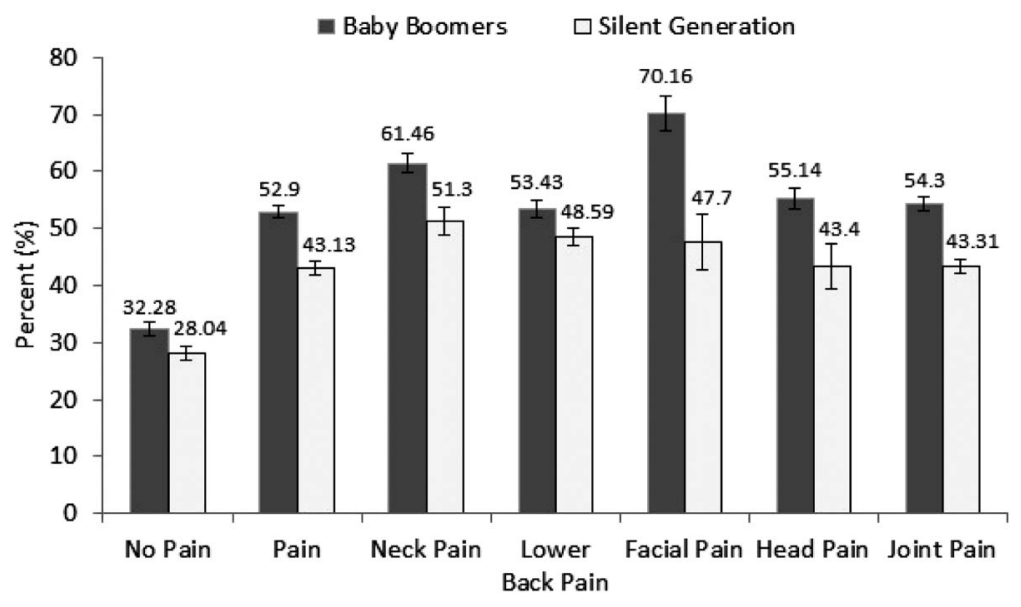

tial use of CAM in the context of chronic illnesses and pain, family physicians need to discuss the risks and benefits of specific CAM approaches with their aging patients to promote safe use of these therapies and effective coping with these conditions.

\section{References}

1. Centers for Disease Control and Prevention. Life expectancy. United States, 2010. Available from: http:// www.cdc.gov/nchs/fastats/life-expectancy.htm. Accessed May 7, 2014.

2. Werner CA. The older population: 2010.2010 Census briefs. Washington, DC: US Census Bureau; 2011. Available from: http://www.census.gov/prod/ cen2010/briefs/c2010br-09.pdf/. Accessed May 7, 2014.

3. American Hospital Association (AHA). When I'm 64: how Boomers will change health care. Chicago, Illinois: AHA; 2007. Available from: http://www.aha.org/ content/00-10/070508-boomerreport.pdf. Accessed May 7, 2014.

4. Centers for Disease Control and Prevention. The burden of chronic diseases and their risk factors: national and state perspectives. February 2004. Available from: http://9healthfair.publichealthpractice.org/documents/ burden_book2004.pdf. Accessed May 7, 2014.

5. Knickman JR, Snell EK. The 2030 problem: caring for aging baby boomers. Health Serv Res 2002;37: 849-84.

6. Mokdad AH, Ford ES, Bowman BA, et al. Prevalence of obesity, diabetes, and obesity-related health risk factors, 2001. JAMA 2003;289:76-9.

7. Seeman TE, Merkin SS, Crimmins EM, Karlamangla AS. Disability trends among older Americans: National Health And Nutrition Examination Surveys, 1988-1994 and 1999-2004. Am J Public Health 2010;100:100-7.
8. National Center for Complementary and Alternative Medicine. Complementary, alternative, or integrative health: what's in a name? Available from: http:// nccam.nih.gov/health/whatiscam/. Accessed May 7, 2014.

9. Barnes PM, Bloom B, Nahin RL. Complementary and alternative medicine use among adults and children: United States, 2007. Natl Health Stat Report. 2008;(12):1-23.

10. Tindle H, Davis R, Phillips R, Eisenberg D. Trends in use of complementary and alternative medicine by US adults: 1997-2002. Altern Ther Health Med 2005;11:42-9.

11. Williamson A, Fletcher P, Dawson K. Complementary and alternative medicine, use in an older population. J Gerontol Nur. 2003;29:20-8.

12. Bell RA, Suerken CK, Grzywacz JG, Lang W, Quandt SA, Arcury TA. CAM use among older adults age 65 or older with hypertension in the United States: general use and disease treatment. J Altern Complement Med. 2006;12:903-9.

13. Cheung CK, Wyman JF, Halcon LL. Use of complementary and alternative therapies in communitydwelling older adults. J Altern Complement Med 2007;13:997-1006.

14. Garrow D, Egede LE. National patterns and correlates of complementary and alternative medicine use in adults with diabetes. J Altern Complement Med 2006;12:895-902.

15. Grzywacz JG, Suerken CK, Quandt SA, Bell RA, Lang W, Arcury TA. Older adults' use of complementary and alternative medicine for mental health: findings from the 2002 National Health Interview Survey. J Altern Complement Med 2006;12:467-73.

16. Mao JJ, Palmer CS, Healy KE, Desai K, Amsterdam J. Complementary and alternative medicine use among cancer survivors: a population-based study. J Cancer Surviv 2010;5:8-17. 
17. Quandt SA, Chen H, Grzywacz JG, Bell RA, Lang $W$, Arcury TA. Use of complementary and alternative medicine by persons with arthritis: results of the National Health Interview Survey. Arthritis Rheum 2005;53:748-55.

18. Saydah SH, Eberhardt MS. Use of complementary and alternative medicine among adults with chronic diseases: United States 2002. J Altern Complement Med 2006;12:805-12.

19. McMahan S. Alternative therapy use among the young-old (ages 65 to 74): an evaluation of the MIDUS database. J Appl Gerontol. 2004;23:12.

20. Arcury TA, Suerken CK, Grzywacz JG, Bell RA, Lang W, Quandt SA. Complementary and alternative medicine use among older adults: ethnic variation. Ethn Dis 2006;16:723-31.

21. National Center for Health Statistics. 2007 National Health Interview Survey (NHIS) public use data release. NHIS survey description. Bethesda, MD: Centers for Disease Control and Prevention, US Department of Health and Human Services; 2008. Available from: ftp://ftp.cdc.gov/pub/Health_Statistics/NCHS/ Dataset_Documentation/NHIS/2007/srvydesc.pdf. Accessed May 27, 2014.

22. Barnes PM, Powell-Griner E, McFann K, Nahin RL. Complementary and alternative medicine use among adults: United States, 2002. Adv Data 2004; (343):1-19.

23. American Statistical Association. Section on survey research methods: summary of survey analysis software; 2005. Available from: http://www.hcp.med. harvard.edu/statistics/survey-soft/. Accessed May 28, 2014.

24. Nahin RL, Barnes PM, Stussman BJ, Bloom B. Costs of complementary and alternative medicine (CAM) and frequency of visits to CAM practitioners: United States, 2007. Natl Health Stat Report 2009; (18):1-14.

25. Leveille SG, Wee CC, Iezzoni LI, eds. Are baby boomers aging better than their predecessors? Trends in overweight, arthritis and mobility difficulty. Chicago: University of Chicago Press; 2009.
26. Berliner HS, Salmon JW. The holistic alternative to scientific medicine: history and analysis. Int J Health Serv 1980;10:133-47.

27. Jonas WB, Levin J, eds. The history of complementary and alternative medicine. Philadelphia: Lippincott Williams \& Wilkins; 1999.

28. White Hourse Commission on Complementary and Alternative Medicine Policy. Chapter 2: Overview of CAM in the United States: recent history, current status and prospects for the future. Available from: http://www.whccamp.hhs.gov/fr2.html. Accessed May 7, 2014.

29. Arcury TA, Bell RA, Snively BM, et al. Complementary and alternative medicine use as health self-management: rural older adults with diabetes. J Gerontol B Psychol Sci Soc Sci 2006;61:S62-70.

30. Birdee GS, Yeh G. Complementary and alternative medicine therapies for diabetes: a clinical review. Clin Diabetes 2010;28:147-55.

31. Astin JA. Why patients use alternative medicine: results of a national study. JAMA 1998;279:1548-53.

32. Hawk C, Ndetan H, Evans MW Jr. Potential role of complementary and alternative health care providers in chronic disease prevention and health promotion: an analysis of National Health Interview Survey data. Prev Med 2012;54:18-22.

33. Vickers AJ, Cronin AM, Maschino AC, et al; Acupuncture Trialists' Collaboration. Acupuncture for chronic pain: individual patient data meta-analysis. Arch Intern Med 2012;172:1444-53.

34. Wang C, Schmid CH, Rones R, et al. A randomized trial of tai chi for fibromyalgia. N Engl J Med 2010; 363:743-54.

35. Sherman KJ, Cherkin DC, Wellman RD, et al. A randomized trial comparing yoga, stretching, and a self-care book for chronic low back pain. Arch Intern Med 2011;171:2019-26.

36. Perlman AI, Sabina A, Williams AL, Njike VY, Katz DL. Massage therapy for osteoarthritis of the knee: a randomized controlled trial. Arch Intern Med 2006; 166:2533-8. 